\title{
Overexpression of Nerve Growth Factor in Epidermis of Transgenic Mice Causes Hypertrophy of the Peripheral Nervous System
}

\author{
Kathryn M. Albers, ${ }^{1,2}$ Douglas E. Wright, ${ }^{2}$ and Brian M. Davis ${ }^{2}$ \\ Departments of ${ }^{1}$ Pathology and ${ }^{2}$ Anatomy and Neurobiology, University of Kentucky College of Medicine, Lexington, \\ Kentucky 40536
}

\begin{abstract}
Survival of developing neurons is dependent on access to a limited supply of target-derived neurotrophic factors. NGF is the most extensively characterized of these molecules and during development is synthesized by neuronal and nonneuronal target tissues such as the skin. To investigate how target-derived NGF affects neuron survival and development of the PNS, we used an epidermal-specific gene promoter to produce transgenic mice that overexpress the mouse NGF CDNA in skin. Analysis of transgenic skin mRNA synthesis by Northern and in situ hybridizations showed increased levels of transgene-derived mRNA in the epidermis and associated hair follicles. The increase in NGF mRNA correlated with a hypertrophy of peripheral sensory and sympathetic nerves. Immunological analysis of skin using an anti-150 $\mathrm{kDa}$ neurofilament antibody showed numerous large nerve bundles and fibers coursing throughout the dermis. Increased numbers of nerve processes in the transgenic skin had immunoreactivity for calcitonin gene-related peptide and tyrosine hydroxylase, indicating that both the sensory and sympathetic systems were hypertrophied. The trigeminal and superior cervical ganglia were greatly enlarged. Cell counts of trigeminal ganglia of control and transgenic mice showed a $26-117 \%$ increase in the number of neurons in the transgenics, Indicating a reduction or total prevention of the program of naturally occurring cell death. These results demonstrate that NGF production by the epidermal target tissue controls neuronal survival, and in so doing, establishes the level of innervation.
\end{abstract}

[Key words: NGF, neurotrophin, transgenic mice, epidermal expression, neuron survival, trigeminal ganglion]

During development of the vertebrate nervous system nearly all groups of ncurons undcrgo a process of naturally occurring cell death (Rogers and Cowan, 1974; Ard and Morest, 1984; Oppenheim, 1991). Neuron death typically occurs shortly after nerves begin to make functional connections within their target field (Oppenheim, 1981). Survival during this period of inner-

\footnotetext{
Received Mar. 9, 1993; revised Aug. 26, 1993; revised Sept. 1, 1993.

We thank Dr. Robert Edwards (UCLA) for providing the NGF cDNA, Dr. Elaine Fuchs (University of Chicago) for the K14-hGH plasmid, Michael Green for transgenic mouse production, Frankie Davis, Teresa Perrone, and Kerstin Lundgren for excellent technical assistance, and Patricia Osborne (Washington University, St. Louis, MO) for carrying out the NGF bioassay. We also thank Drs. Christine Gall, Eugene Johnson, and Steven Scheff for their helpful comments on the manuscript. This work was supported by grants from the ACS (Institutional Research Grant IN-163) and NIH (BRSG RO5374 and AR40873 and NS31826).

Correspondence should be addressed to Kathryn Albers, Department of $\mathrm{Pa}$ thology, 800 Rose Street, University of Kentucky, Lexington, KY 40536-0093. Copyright (C 1994 Society for Neuroscience $0270-6474 / 94 / 141422-11 \$ 05.00 / 0$
}

vation is thought to be dependent on neurons acquiring access to a limited quantity of neurotropic substance provided by the target field (Thoenen and Barde, 1980; Davies et al., 1991; Oppenheim, 1991). The competition for neurotrophic factors is thought to serve at least two functions: to ensure that an appropriate number of synaptic contacts are made and to eliminate inappropriate neuronal projections (Oppenheim, 1981; Cowan et al., 1984). This concept is referred to as the neurotrophic hypothesis and predicts that the number of neurons in the adult could be increased if a higher concentration of neurotrophic factor(s) was available during the critical time when synaptic contacts are being established. NGF is a prototypical target-derived neurotrophic substance that has been shown to be essential for the survival and differentiation of neural crestderived sensory neurons and sympathetic neurons in the PNS (Levi-Montalcini and Angeletti, 1968; Johnson and Yip, 1985). The role of NGF in neuron survival is supported by numerous studies that have utilized both tissue culture and in vivo approaches in which NGF peptide or NGF antibodies were applied (Levi-Montalcini and Booker, 1960a,b; Barde et al., 1980; Johnson et al., 1980; Hamburger and Yip, 1984). Sympathetic and certain sensory neurons can be rescued by exogenous NGF whereas anti-NGF antibodies eliminate these neurons.

During development of skin, NGF is expressed by target cells of the presumptive epidermis and dermis (Davies et al., 1987; Schecterson and Bothwell, 1992). Target-field synthesis of NGF coincides with the arrival of axons to the epidermis, though the onset of expression and the concentration of NGF are independent of innervation (Korsching and Thoenen, 1983; Shelton and Reichardt, 1984; Rohrer et al., 1988; Harper and Davies, 1990). Thus, cells of the target field appear to determine the onset and level of NGF gene expression. In mouse whisker pad skin, time course studies of innervation have shown that by embryonic day 11 (E11) nerve fibers have grown to the skin and NGF mRNA expression has begun (Davies et al., 1987). NGF production continues to rise until E14 and then falls sharply by E15. The decrease in NGF concentration coincides with the cell death of nearly half of the neurons in the trigeminal ganglion.

As skin innervation proceeds, the embryonic epithelium begins the transformation from a two-cell-layer, undifferentiated periderm to a multilayer, stratified epidermis (Schweizer and Winter, 1982; Kopan and Fuchs, 1989). The differentiation of the epidermis is marked by the expression of epidermal-specific genes, one of the earliest being the gene encoding the keratin intermediate filament protein $\mathrm{K} 14$. The onset of $\mathrm{K} 14$ gene expression in mouse skin occurs at approximately E14-E15 (Schweizer and Winter, 1982; Kopan and Fuchs, 1989), beginning as NGF concentration is declining. To investigate the role 
of NGF in the development of the PNS and skin innervation, we utilized the human $\mathrm{K} 14$ gene promoter to drive the expression of the NGF cDNA in epidermal keratinocytes. Our results show that overexpression of NGF by the cutaneous target has profound effects on the level of skin innervation and neuronal survival.

\section{Materials and Methods}

\section{Construction of K14-NGF transgene and introduction into}

mice

Plasmid pKS-NGF (a gift from R. Edwards, UCLA) was cut with ApaI $(+230)$ and PstI $(+1027)$ to remove a 797 base pair fragment that encodes the NGF short transcript (Edwards et al., 1989). The overhanging ends of the ApaI-PstI NGF fragment were removed using mung bean nuclease and the fragment was gel purified and ligated into BamHI cut, Klenow filled K14-hGH cassette vector (Cheng et al., 1992). K14hGH contains 2.1 kilobase pairs $(\mathrm{kbp})$ of 5 ' upstream sequence (promoter and enhancer) of the human $\mathrm{K} 14$ keratin gene and a $1.8 \mathrm{kbp}$ intron containing sequence from the human growth hormone (hGH) gene. The hGH sequence serves to upregulate expression of the transgene and provides a polyadenylation signal (Sandgren et al., 1990). The 5 kbp K14-NGF-hGH EcoRI fragment (Fig. la) was isolated on a $0.8 \%$ Seaplaque agarose gel (FMC Corporation), extracted from the gel using glassmilk purification (Geneclean Bio 101), and run through an NACS column (Bethesda Research Laboratories). Collected DNA was ethanol precipitated, resuspended in phosphate-buffered saline (PBS) at a concentration of $5 \mu \mathrm{g} / \mathrm{ml}$, and microinjected into fertilized C3HB6 F1 mouse embryos (Harlan Laboratory Supplies). Injections and implantations were carried out using standard procedures (Hogan et al., 1986). Mice were screened for the transgene using Southern hybridization analysis on DNA extracted from tail or using the polymerase chain reaction on DNA isolated from ear punches. Polymerase chain reaction primers were made to sequences unique to the $\mathrm{K} 14$ and $\mathrm{hGH}$ regions flanking the NGF cDNA. For Southern hybridizations, $10 \mu \mathrm{g}$ of DNA was digested with PstI, separated on an $0.7 \%$ agarose gel, and transferred to nitrocellulose by blotting. The membrane was incubated with a randomprimed ${ }^{32} \mathrm{P}-\mathrm{dCTP}$ (New England Nuclear) labeled probe made to the full-length NGF cDNA. Probe hybridization was carried out for $16 \mathrm{hr}$ at $42^{\circ} \mathrm{C}$ in the presence of $50 \%$ formamide, after which the membrane was washed and exposed to film.

\section{Analysis of $m R N A$ expression}

Northern hybridization Northern analysis was performed on RNA that was isolated from various tissues using guanidium thiocyanate/phenol/ chloroform extraction (Chomczynski and Sacchi, 1987). Ten micrograms of total RNA were resolved on a $1.2 \%$ agarose formaldehyde denaturing gel, transferred to Nytran membrane (Schleicher and Schuell) by blotting, baked $2 \mathrm{hr}$ at $80^{\circ} \mathrm{C}$, and then hybridized at $42^{\circ} \mathrm{C}$ in the presence of $50 \%$ formamide to a ${ }^{32} \mathrm{P}$-dCTP-labeled random-primed probe made to the full-length NGF cDNA. The membrane was hybridized for $18 \mathrm{hr}$, washed, and exposed to film.

In situ hybridization. ${ }^{35}$ S-labeled cRNA probes were generated by adding $1 \mu \mathrm{g}$ of linearized pKS-NGF plasmid (linearized with SacI for an antisense probe and EcoRI for a sense probe) to $2.5 \mathrm{~mm}$ each ATP, CTP, GTP, $15 \mathrm{mM}^{3}{ }^{3} \mathrm{~S}-\mathrm{UTP}$ (New England Nuclear), and either T7 or T3 polymerase (Stratagene) to generate antisense and sense probes, respectively. Incubation was for $60 \mathrm{~min}$ at $37^{\circ} \mathrm{C}$ in transcription buffer

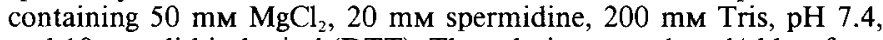
and $10 \mathrm{~mm}$ dithiothreitol (DTT). The solution was phenol/chloroform extracted and precipitated with ammonium acetate and $2.5 \mathrm{vol}$ of ethanol in the presence of $25 \mu \mathrm{g}$ of carrier tRNA.

For in situ hybridization, mouse whisker pad skin was dissected, immediately frozen on dry ice, cryostated at $10-20 \mu \mathrm{m}$, mounted onto Vectabond-coated slides (Vector Labs), and stored at $-80^{\circ} \mathrm{C}$ until hybridized. For hybridization, slides were brought to room temperature, fixed for $10 \mathrm{~min}$ in $4 \%$ paraformaldehyde, washed in diethyl pyrocarbonate-treated phosphate buffer, transferred to $0.25 \%$ acetic anhydride in $0.1 \mathrm{M}$ tetraethylammonium, $\mathrm{pH} 8.0$, for $10 \mathrm{~min}$ at room temperature, dehydrated through a graded series of alcohols, and defatted in chloroform. Sections were hybridized for $12-24 \mathrm{hr}$ at $60^{\circ} \mathrm{C}$ in a hybridization solution consisting of $1 \times 10^{7} \mathrm{cpm} / \mathrm{ml}$ of ${ }^{35} \mathrm{~S}$-labeled cRNA probe, $50 \%$ formamide, $1 \times$ Denhardt's solution, $200 \mathrm{~mm}$ Tris pH 7.5, 10\% dextran sulfate, $0.3 \mu \mathrm{g} / \mathrm{ml}$ salmon sperm DNA, $0.15 \mathrm{mg} / \mathrm{ml} \mathrm{tRNA}$, and $40 \mathrm{~mm}$
DTT. Slides were washed in $4 \times \mathrm{SSC}(1 \times \mathrm{SSC}=0.15 \mathrm{M} \mathrm{NaCl}, 0.015$ M sodium citrate, $\mathrm{pH} 7.0$ ), incubated in $20 \mathrm{mg} / \mathrm{ml}$ ribonuclease A (Sigma) dissolved in $10 \mathrm{~mm}$ Tris-saline, and washed through descending concentrations of SSC. The final wash was $0.1 \times \mathrm{SSC}$ at $37^{\circ} \mathrm{C}$ for $1 \mathrm{hr}$. Sections were air dried and placed in $\mathrm{x}$-ray cassettes with Hyperfilm $\beta$-Max x-ray film (Amersham). Films were exposed for 3-7 d and developed in Kodak D-19. Selected slides were dipped in Kodak NTB-2 liquid emulsion, air dried, and exposed to film. Emulsion dipped slides were developed in D19, fixed in Kodak rapid fixer, counterstained with hematoxylin/eosin or cresyl violet, and coverslipped in Permount. Skin sections from transgenic mice and nontransgenic siblings were processed in parallel. Controls for probe specificity included hybridization using a sense cRNA probe and pretreatment of tissue with RNase. Both of these conditions resulted in the absence of hybridization.

\section{Cell counts of trigeminal neurons}

Cell counts were obtained using the method of Coggeshall et al. (1984, 1990) based on a determination of the number of neuronal nucleoli. Animals were placed under deep anesthesia and perfused transcardially with $4 \%$ paraformaldehyde in $0.1 \mathrm{~m}$ phosphate buffer, $\mathrm{pH} 7.4$. Trigeminal ganglia were removed and immersion fixed in $4 \%$ paraformaldehyde, dehydrated in alcohol, defatted, and embedded in paraffin. Entire ganglia were serial sectioned at $8 \mu \mathrm{m}$ and stained with hematoxylin and eosin. Every 10 th section was examined at a total magnification of $400 \times$ and a drawing tube was used to trace the outline of the section and to demarcate the location of each sensory neuron containing a nucleolus. To compensate for neurons with two or more nucleoli, profiles of randomly selected neurons were reconstructed and the total number of nucleoli per 100 neurons was determined. This provided a nucleolus: neuron ratio that was multiplied by the total neurons counted to obtain the total number of neurons per ganglion (Coggeshall et al., 1990).

\section{Immunocytochemistry}

Tissue was immersed in fixative for $90 \mathrm{~min}$, transferred to $20-30 \%$ sucrose in PBS, and incubated overnight at $4^{\circ} \mathrm{C}$. Samples were cryostated at $10 \mu \mathrm{m}$, thaw mounted onto Vectabond-coated glass slides, and processed for immunolabeling. Primary antibodies recognizing the following antigens were used: the $150 \mathrm{kDa}$ neurofilament protein (NF 150; 1:300 dilution; Chemicon), calcitonin gene-related peptide (CGRP; $1: 200$ dilution; Chemicon), tyrosine hydroxylase (TH; 1:100 dilution; Chemicon). For NF 150 labeling, frozen sections were air dried for $10 \mathrm{~min}$, fixed $10-15 \mathrm{~min}$ in $-20^{\circ} \mathrm{C}$ acetone, air dried, rehydrated in PBS, and incubated in primary antibody solution. Binding of the NF 150 antibody was visualized using a goat anti-rabbit $\mathrm{IgG}$ fluorescein isothiocyanateconjugated secondary antibody (Cappel Laboratories). Sections labeled for CGRP and TH were incubated with primary antibody (diluted in PBS containing $1 \%$ normal goat serum and $0.3 \%$ Triton X-100) $18-24$ $\mathrm{hr}$ at $4^{\circ} \mathrm{C}$ in a humidified chamber and rinsed in PBS for 30 min (three changes). Visualization of CGRP and TH immunoreactivity was achieved using avidin-biotin-peroxidase complex $(\Lambda \mathrm{BC})$ (kit from Vector Labortories) (Hsu et al., 1981). After primary antibody incubation, sections were washed twice in PBS ( 5 min each) incubated in biotinylated goat anti-rabbit secondary antibody for $30 \mathrm{~min}$, washed in PBS, and incubated in the ABC complex for 30 min. Following two PBS washes, immunoreactivity was visualized by incubation in $0.025 \% 3,3^{\prime}$-diaminobenzidine $4 \mathrm{HCl}$ (Aldrich) with $0.05 \% \mathrm{H}_{2} \mathrm{O}_{2}$ and $1.5 \%$ nickel ammonium sulfate dissolved in $0.1 \mathrm{~m}$ sodium acetate buffer, $\mathrm{pH} 6$, for 7 $\min$.

\section{Results}

\section{Expression of K14-NGF in skin of transgenic mice}

NGF was overexpressed in the epidermis of transgenic mice using a fusion gene construct in which the human epidermal K14 keratin promoter and enhancer sequences were linked to a mouse NGF cDNA (Fig. 1a). The K14 promoter has previously been shown to direct high-level expression of various transgenes to basal keratinocytes of the epidermis (Vassar et al., 1989, 1991; Cheng et al., 1992). The rationale in designing the K14-NGF construct was based on the temporal overlap of NGF downregulation with the initiation of $\mathrm{K} 14$ expression; that is, as the concentration of target-derived NGF begins to fall and 


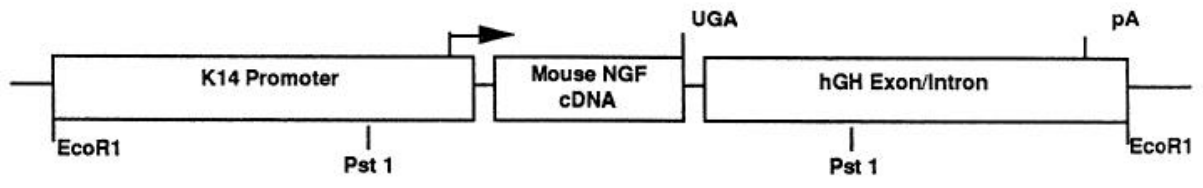

a

200 bp

Figure 1. Transgene construct and characterization of transgenic expression. $a$, The K14-NGF fusion gene contains the mouse NGF cDNA cloned downstream of the human epidermal $\mathrm{K} 14$ gene promoter and enhancer sequences (Vassar et al., 1989). A fragment containing a partial sequence of the hGH gene was ligated downstream of the NGF insert to provide an introncontaining sequence and polyA $(p A)$ addition signal. Arrow indicates transcription start site. $b$, Schematic depicting the onset of NGF expression by E11, and its rise and fall at E15. As the endogenous level of NGF decreases, expression of the K14-NGF transgene begins, rises to a steady level, and continues in the adult skin. Actual relative levels of expression are not implied. $c$, Mice were screened for the transgene by Southern hybridization of DNA isolated from tail samples obtained 3-4 weeks after birth. Blots were probed using a ${ }^{32} \mathrm{P}$-labeled DNA sequence complementary to the mouse NGF cDNA. The NGF probe detects both the transgene at $1.8 \mathrm{kbp}$ (arrowhead) and the single-copy, endogenous NGF gene ( $1.58 \mathrm{kbp}$ band below the transgene). Three founder animals were isolated: lane 1, A-39; lane 2, A-47; lane 3, A-56; lane 4 , nontransgenic control.

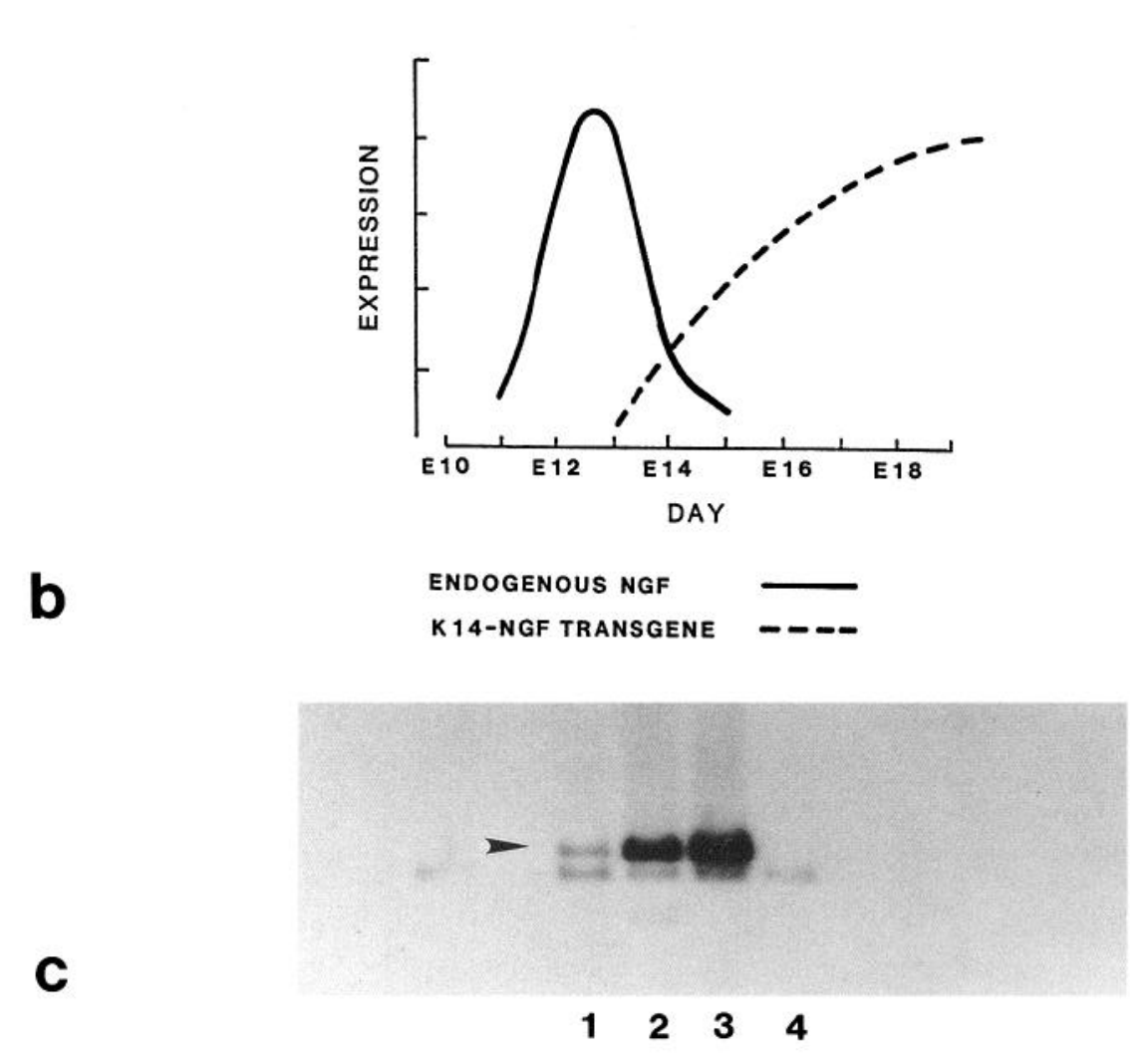

neuronal cell death commences (E14-E15), the K14-NGF transgene turns on, producing elevated levels of NGF during the critical period of cell death and thereafter in the adult (Fig. $1 b$ ).

Three founder mice were isolated that expressed the transgene: A-39, A-47, and A-56 (Fig. 1c). Founder A-39 (Fig. 1c, lane 1) and founder A-56 (lane 3) were smaller and exhibited a low rate of weight gain, similar to mice injected with NGF peptide (Levi-Montalcini and Booker, 1960a). By approximately 10 weeks of age they had gained weight to within a normal range. Founder A-39 did not generate transgenic offspring, though approximately 80 offspring have been screened, whereas A-56 and A-47 did. Many offspring of founder A-56 also exhibited reduced weight gain (up to $\sim 40 \%$ of control values) as opposed to founder A-47 and her offspring, which were consistently normal in size.

To determine the relative level of K14-NGF expression in the three transgenic lines, Northern hybridization analysis of total RNA isolated from full-thickness skin was performed (Fig. $2 a$ ). Nontransgenic skin samples (Fig. $2 a$, lane 1) had a single faint band that hybridized with a radiolabeled NGF probe at approximately 1.3 kilobases $(\mathrm{kb})$, a size corresponding to the endogenous RNA transcript (Ullrich et al., 1983). RNA samples isolated from A-39 (Fig. 2, lane 2), A-47 (lane 3), and A-56 (lane 4 ) skin contained, in addition to the endogenous transcript (slightly visible with this exposure), an approximate $1.9 \mathrm{~kb}$ band that corresponded to the predicted size of the K14-NGF transcript. Lines A-39 and A-47 had comparable levels of transgene expression whereas expression in the A-56 line was significantly higher.

The tissue specificity of the K14 promoter and enhancer region has previously been shown to be restricted to stratified, keratinized tissues that express the K14 keratin such as skin, tongue, esophagus, and forestomach (Vassar et al., 1989). To verify that the tissue distribution of K14-NGF expression was comparable, RNA was analyzed from tongue, brain, heart, liver, and kidney of an A-56 F1 transgenic and nontransgenic control. As expected, expression of the K14-NGF transgene in the A-56 transgenic was confined to the samples of keratinized epithelium of the skin (Fig. 2, lanes 2-5) and tongue (lane 6). Endogenous NGF gene expression was easily detected in brain (Fig. 2, lanes 7,13 ), heart (lanes 8, 14), and kidney (lanes 10, 16) of both transgenic and control tissues. Transgenic and control liver RNA (lanes 9, 15) and control tongue RNA (lane 12) showed no evidence of NGF expression.

Cellular expression of the K14-NGF transgene was examined using in situ hybridization on sections of whisker pad skin, a region known to have a high level of innervation (Fig. 3). $\mathrm{A}^{35} \mathrm{~S}$ labeled cRNA probe specific for the mouse NGF mRNA was 

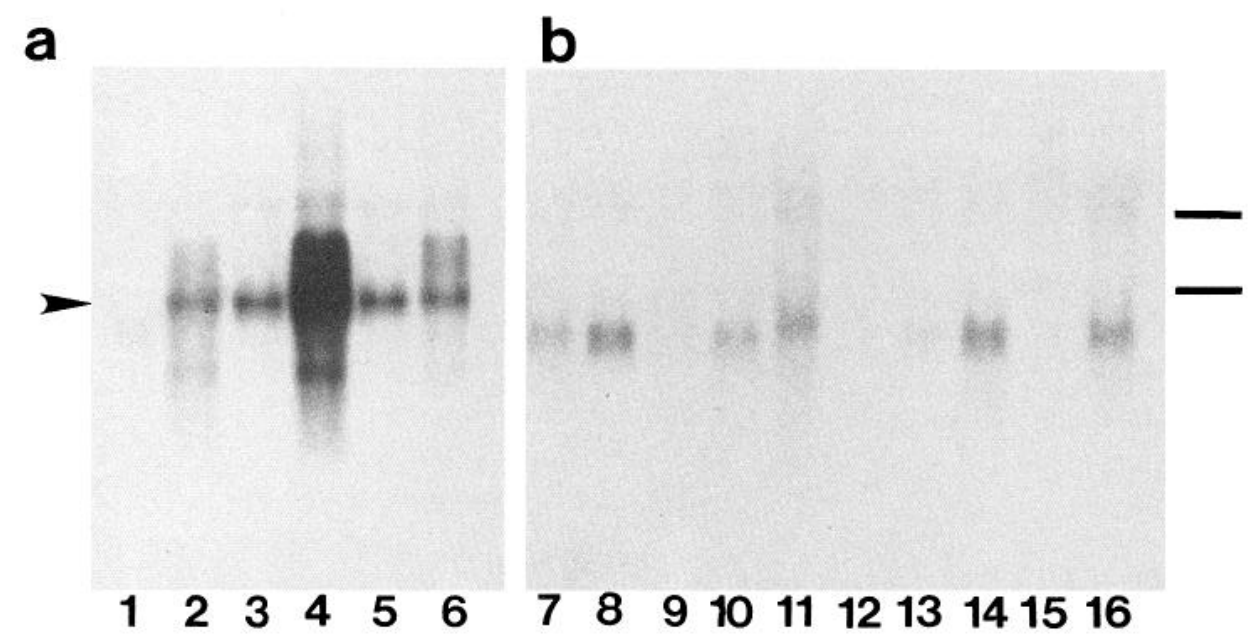

\section{$\begin{array}{lllllllllllllll}1 & 2 & 3 & 4 & 5 & 6 & 7 & 8 & 9 & 10 & 11 & 12 & 13 & 1415 & 16\end{array}$}

Figure 2. Expression of the K14-NGF transgene is tissue specific. $a$, To examine the expression level of the K14-NGF transgene for each line, RNA was isolated from full-thickness skin of 4-6-week-old F1 mice and analyzed using Northern hybridization. Ten micrograms of total RNA were resolved on a formaldehyde denaturing gel, transferred to Nytran membrane, and probed with a ${ }^{32} \mathrm{P}-$ labeled DNA sequence complementary to the NGF mRNA. All samples were loaded onto a single gel. Two film exposures were done in order to detect the low-level expression of endogenous NGF transcript. Shown is a $3 \mathrm{~d}$ exposure $(a)$ and a $10 \mathrm{~d}$ exposure $(b)$ of the same filter. Lane 1, Skin RNA of nontransgenic control. A faint band is visible at $1.3 \mathrm{~kb}$ corresponding to the endogenous NGF transcript. Lane 2, RNA from tail skin of A-39 founder. Transgene mRNA band (arrowhead) is apparent at the predicted size of $1.9 \mathrm{~kb}$. Lane 3, Skin RNA of A-47 F1. Lane 4, Skin RNA of A-56 F1. Lane 5, Skin RNA of A-47 F1 (loaded twice). Lane 6, Tongue RNA of A-56 F1. Tongue is a keratinized, K14 keratin-expressing structure expected to have transgene expression. $b$, To examine the tissue specificity of K14-NGF expression, RNA from brain (lane 7, A-56; lane 13, control), heart (lane 8, A-56; lane 14, control), liver (lane 9, A-56; lane 15, control), and kidney (lane 10, A-56; lane 16, control) were tested. Transgene expression was not evident in these structures, though the $1.3 \mathrm{~kb}$ endogenous NGF transcript could be detected in all but liver samples. Lane 11, control skin RNA; lane 12, control tongue RNA. The $28 \mathrm{~S}$ and $18 \mathrm{~S}$ ribosomal RNA size markers are indicated by bars on the right.

hybridized to skin sections of 4-week-old K14-NGF transgenics and nontransgenic controls and processed for autoradiography. Few autoradiographic grains were observed in the control skin (Fig. $3 a$ ) whereas the K14-NGF skin showed dense hybridization in the epidermal basal cell layer with decreasing intensity in suprabasal layers (Fig. $3 b$ ). Dense hybridization was also found in basal epidermal cells of the outer root sheath of hair and vibrissa follicles of transgenic mice (Fig. $3 d$ ), but not in the corresponding areas of the control (Fig. $3 c$ ). The epidermal and hair follicle distribution of hybridization is consistent with the known expression pattern of the K14 keratin (Schweizer and Winter, 1982; Kopan and Fuchs, 1989).

\section{K14-NGF expression induces hyperinnervation of skin}

To determine whether the increased level of NGF mRNA in the transgenic epidermis was processed into functional NGF peptide, we examined the skin for evidence of increased neuronal processes that would be indicative of increased neuron survival. Histological examination of skin from various regions of the body (dorsum, ventral, tail, ear, footpad, and whisker pad locations) revealed an increase in nerve processes and an abundance of large nerve bundles coursing throughout the reticular layer of the dermis (Fig. $4 a-c$, control; $d-f$, transgenic). To confirm that these structures were composed of neuronal processes, whisker pad skin from A-56 F1 mice was immunolabeled with an antibody directed against the $150 \mathrm{kDa}$ neurofilament protein (Fig. $5 a$, control; $b$, transgenic). In control mice, neurofilamentpositive fibers and bundles were evident in the reticular and deep layers of the dermis (Fig. $5 a$, arrowheads). Small, labeled fibers could also be found penetrating the lower layers of the epidermis and associated with hair follicle and vibrissal structures (Fig. $5 a$, arrow). A striking increase in the density and size of neuronal processes was apparent in skin of A-56 transgenics (Fig. $5 b$ ). Hyperinnervation was present in regions subjacent to the epidermis, in the dermis, and around hair follicle structures. Hyperinnervation was also apparent in skin of A-47 F1 mice, though at a reduced level than in the A-56 transgenics (not shown). No major alteration in histology of the transgenic skin was detected, though in some skin samples from A-56 transgenics, the muscle layer subjacent to the dermis appeared thinner than that of controls. This may have resulted from the overall weight and size reduction of the transgenics.

Two primary sources of axons for the observed whisker pad hyperinnervation are sensory neurons originating in the trigeminal ganglion and sympathetic postganglionic fibers arising from the superior cervical ganglion. As a first step in determining the contribution from these two sources, immunocytochemistry was performed using antibodies directed against the neurotransmitter CGRP (Fig. 6a,b), for identification of sensory neurons (Gibbins et al., 1987), and the catecholamine-synthesizing enzyme TH (Fig. $6 c, d$ ), for identification of postganglionic sympathetic axons (Rothman et al., 1980). CGRP is enriched in sensory nerves projecting to hair follicles and free nerve endings in the epidermis (Kruger et al., 1989; Shotzinger and Landis, 1990). Few CGRP-positive fibers could be identified in control skin (Fig. 6a), whereas the K14-NGF transgenic skin had numerous small and large bundles of CGRP-labeled fibers (Fig. $6 b$, arrowheads). CGRP-positive fibers were distributed throughout the dermis and surrounding vibrissa structures (Fig. $6 b$ ). Labeling was particularly evident in the reticular layer of the epidermis where abundant axon terminations normally occur.

Sympathetic innervation of transgenic skin was also enhanced as shown by an increase in TH-immunoreactive fibers (Fig. $6 c$, control; $d$, transgenic). Sympathetic neurons innervate blood vessels, sweat glands, and the erector pili muscles of hair shafts. Whereas control whisker pad skin showed few TH-immunoreactive fibers (Fig. $6 c$ ), the A-56 transgenic skin displayed abun- 

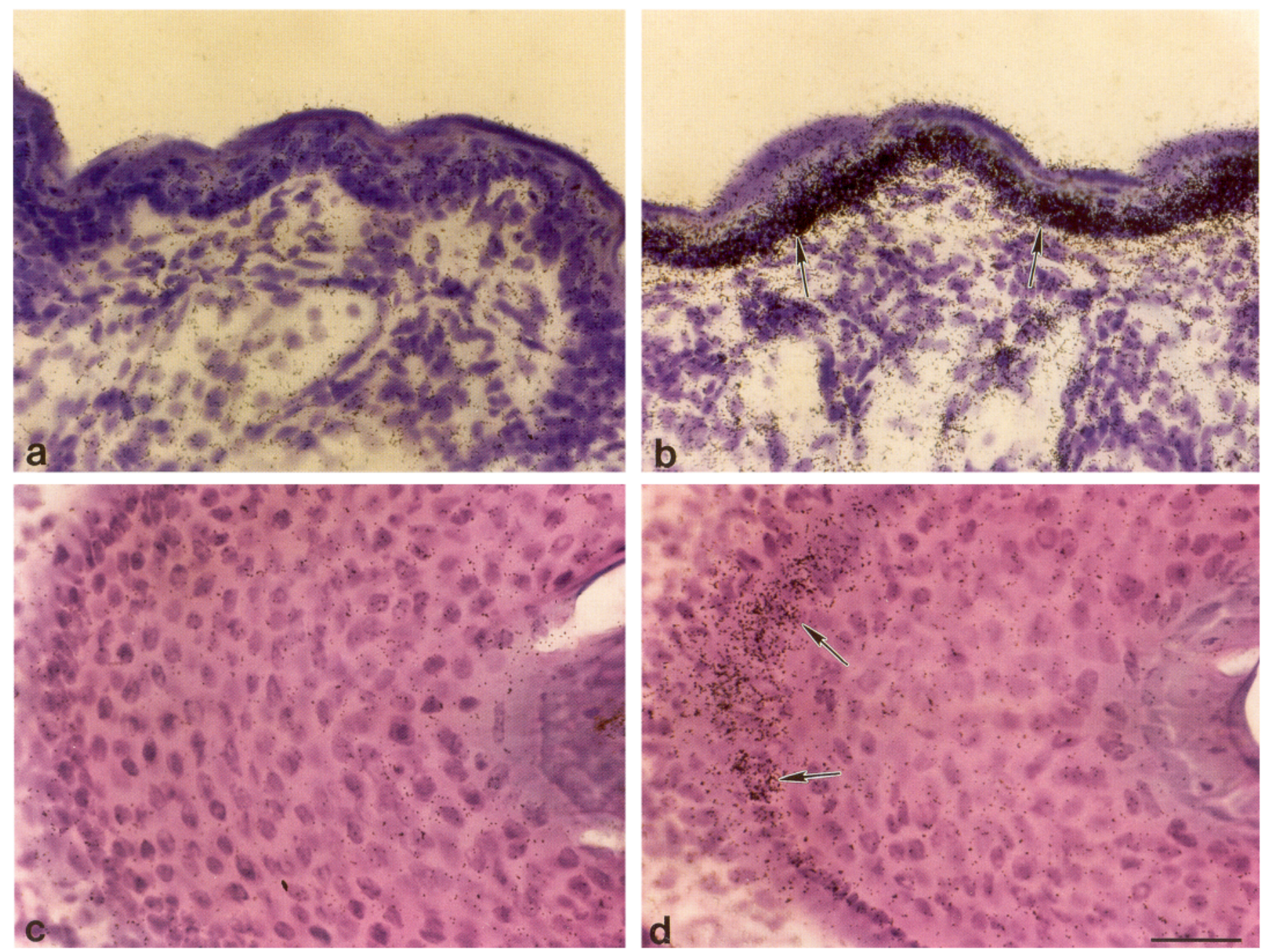

Figure 3. K14-NGF transgene produces elevated levels of NGF mRNA in skin. Cellular expression of the K14-NGF transgene in skin from A-56 F1 transgenics was examined by in situ hybridization. ${ }^{35}$ S-labeled cRNA sense and antisense probes were hybridized to frozen sections of whisker pad skin of 23-d-old A-56 F1 transgenic and control littermate. Epidermis of whisker pad skin $(a)$ and vibrissa $(c)$ in control animals had silver grain densities at background levels. Transgenic skin showed increased grain density over basal cells (arrows) of whisker pad epidermis $(b)$ and vibrissal structures $(d)$. Control hybridizations using a sense riboprobe showed background levels of hybridization. Counterstaining of tissues was done using either cresyl violet $(a, b)$ or hematoxylin and eosin $(c, d)$. Scale bar, $50 \mu \mathrm{m}$.

dant TH labeling (Fig. $6 d$ ). TH labeling of transgenic skin was predominantly found as large fiber bundles in the dermis (Fig. $6 d$, arrowheads), similar to those observed with CGRP labeling. However, under closer examination morphological differences between the CGRP and TH fiber types were apparent in that TH-labeled fibers were thinner and had numerous swellings whereas CGRP-positive fibers appeared thicker and more uniform along their length.

\section{K14-NGF expression induces hypertrophy of trigeminal and superior cervical ganglion}

The availability of elevated levels of NGF peptide to neurons in the epidermal target field of the transgenics was further indicated by a striking hypertrophy of the trigeminal ganglion (Fig. $7 a$, from left to right: control ganglia, A-47 ganglia, A-56 ganglia) and the superior cervical ganglion (Fig. $7 b$, from left to right: control ganglia, A-47 ganglia, A-56 ganglia). To determine whether the hypertrophy of the ganglia resulted from increased neuronal survival, cells were counted in the trigeminal ganglion of control and A-56 F1 transgenic mice (Table 1). The number of cells from three transgenics ranged from $26 \%$ to $117 \%$ greater than nontransgenic, age-matched controls (Table 1). The counts obtained were similar to ones reported for the trigeminal ganglion at a time prior to the onset of naturally occurring cell death (Davies and Lumsden, 1984). These results indicate that overproduction of NGF by the epidermis enhances neuron survival and may prevent cell death entirely.

\section{Discussion}

We have utilized a transgenic mouse model system to study the role of target field-derived NGF in development of the PNS. Elevation of the production of NGF mRNA by the epidermal target tissue correlated with a dramatic increase in neuronal survival, as evidenced by a striking hyperinnervation of the skin and hypertrophy of the trigeminal and superior cervical ganglia. Both sensory and sympathetic neurons innervating the trans- 

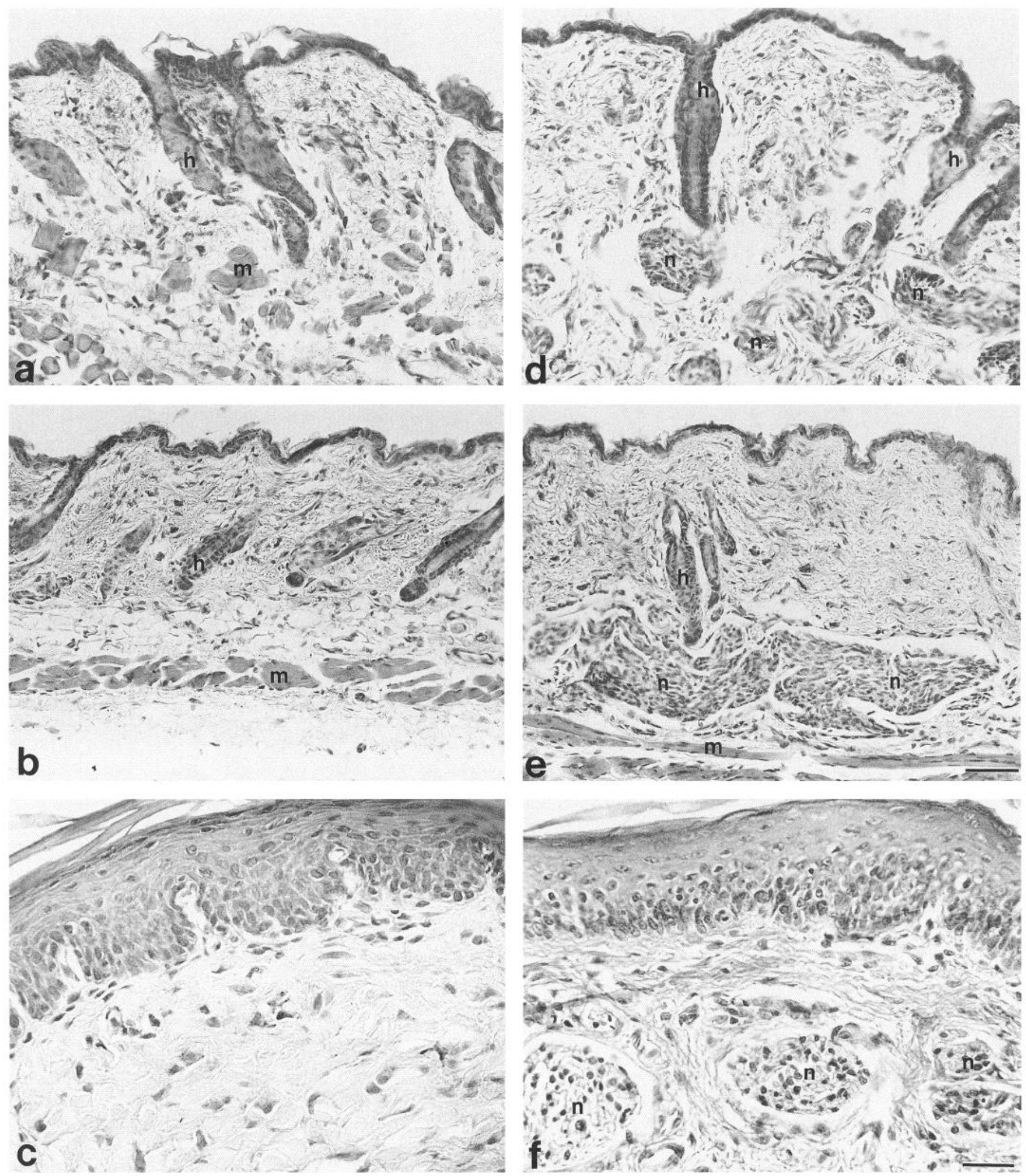

Figure 4. Expression of K14-NGF causes hyperinnervation of skin. Overproduction of NGF by the epidermis caused a hyperinnervation that was evident histologically. Skin samples from whisker pad ( $a$, control; $d$, A-56 transgenic), dorsum ( $b$, control; $e$, A-56 transgenic), and footpad skin ( $c$, control; $f, \mathrm{~A}-47$ transgenic) were processed for paraffin histology and sections stained with hematoxylin and eosin. Control skin ( $a-c)$ had few apparent nerve bundles whereas transgenic skin $(d-f)$ showed numerous, enlarged fiber bundles. $h$, hair; $m$, muscle; $n$, nerve. Scale bars: $e, 25$ $\mu \mathrm{m}$ for $a, b, d$, and $e ; f, 50 \mu \mathrm{m}$ for $c$ and $f$. 

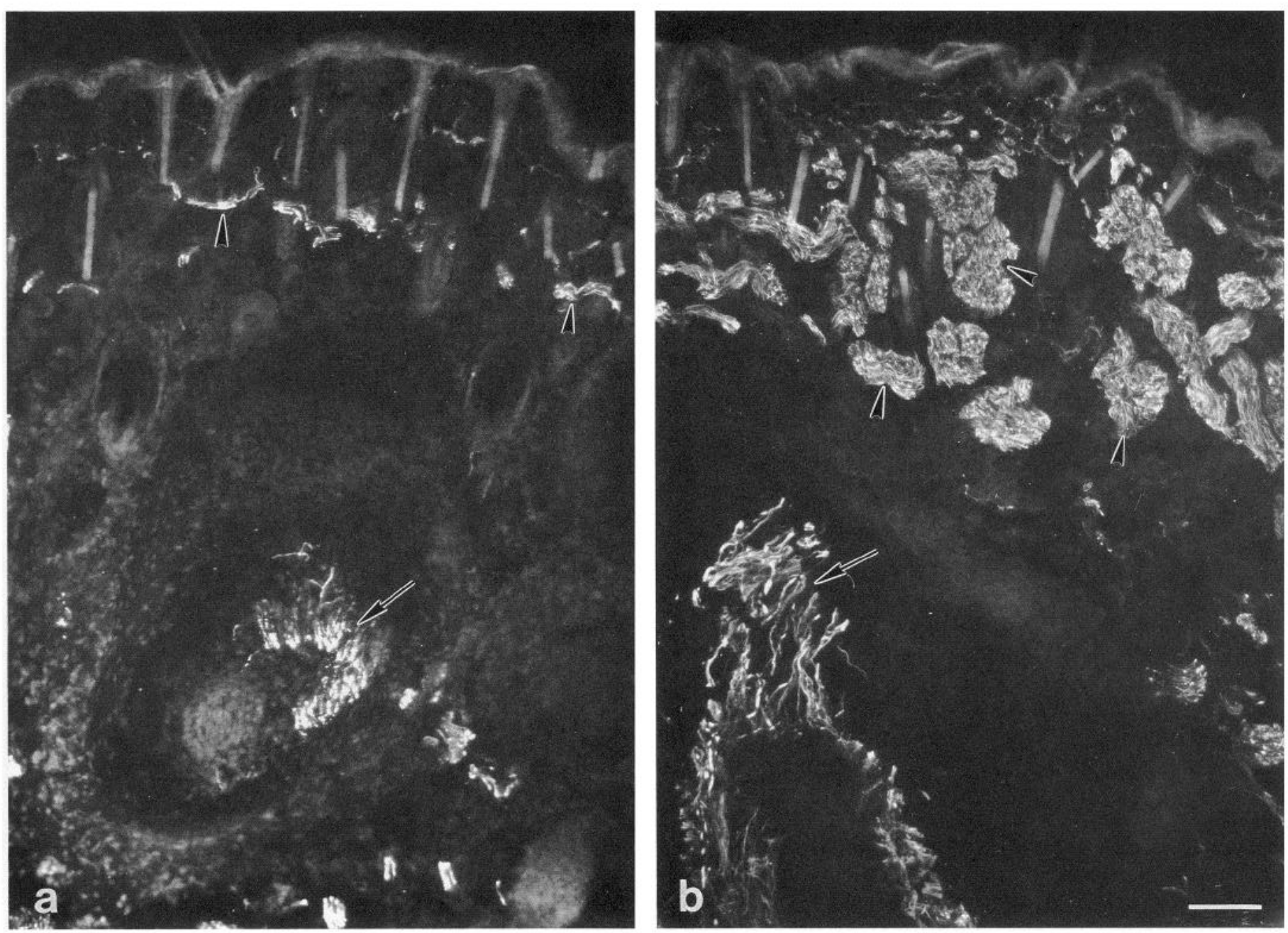

Figure 5. Immunolabeling of transgenic skin using a anti-neurofilament antibody. To verify that the fiber bundles in the skin were composed of neuronal processes, frozen sections of whisker pad skin from $21 \mathrm{~d}$ old control $(a)$ and A-56 F1 transgenic $(b)$ were immunolabeled with an antiNF 150 antibody followed by incubation with a goat anti-rabbit FITC-conjugated secondary. Control skin showed immunoreactive fibers (arrowheads) in the papillary and reticular layers of the dermis, in the deep dermis, and around hair follicles and vibrissa (arrow). A significant increase in the number and density of fibers and bundles was seen in equivalent regions in the A-56 F1 transgenic skin $(b)$. Scale bar, $50 \mu \mathrm{m}$.

genic skin appeared to be rescued by the increased NGF production, as evidenced by enhanced CGRP and TH immunoreactivity. That both sensory and sympathetic neuron populations had increased survival is consistent with the known NGF dependence of these cells during embryonic development and in early postnatal periods (Johnson et al., 1980). For sym-

Table 1. Cell counts of trigeminal ganglion of A-56 K14-NGF transgenic mice and matched sibling controls

\begin{tabular}{llll} 
Case number & Age & $\begin{array}{l}\text { Number of } \\
\text { neurons }\end{array}$ & $\begin{array}{l}\text { centage } \\
\text { differ- } \\
\text { ence }\end{array}$ \\
\hline 0401 Nontransgenic & $24 \mathrm{~d}$ & 26,054 & \\
0401 K14-NGF transgenic & $24 \mathrm{~d}$ & 40,285 & 55 \\
0527 Nontransgenic & $29 \mathrm{~d}$ & 26,493 & \\
0527 K14-NGF transgenic & $29 \mathrm{~d}$ & 57,767 & 117 \\
0513 Nontransgenic & $36 \mathrm{~d}$ & 28,867 & \\
0513 K14-NGF transgenic & $36 \mathrm{~d}$ & 36,562 & 26 \\
\hline
\end{tabular}

pathetic neurons NGF dependency persists into adulthood, though at a reduced level (Angeletti et al., 1971; Gorin and Johnson, 1980; Ruit et al. 1990). Since expression of the K14NGF transgene begins at E14-E15, rises, and continues at a steady level in the adult, both sensory and sympathetic neurons would be exposed to elevated NGF at critical times in their development.

Skin of K14-NGF transgenics exhibited an increase in fibers expressing CGRP and TH immunoreactivity, though the question arises as to whether a true increase in the number of immunoreactive fibers occurred. NGF upregulates CGRP mRNA expression in cultured adult dorsal root ganglion neurons (Lindsay and Harmer, 1989) and in vivo (Donnerer et al., 1992), and also specifically induces the rate-limiting enzyme TH in sympathetic neurons (Thoenen and Barde, 1980). Thus, it is possible that the same number of one or both fiber types were present, but that they contained increased levels of antigen, making detection more efficient. However, the major increase in overall neuron processes detected by NF 150 immunolabeling and the hypertrophy of both sensory and sympathetic ganglia argue that survival of both neuron types was enhanced. 

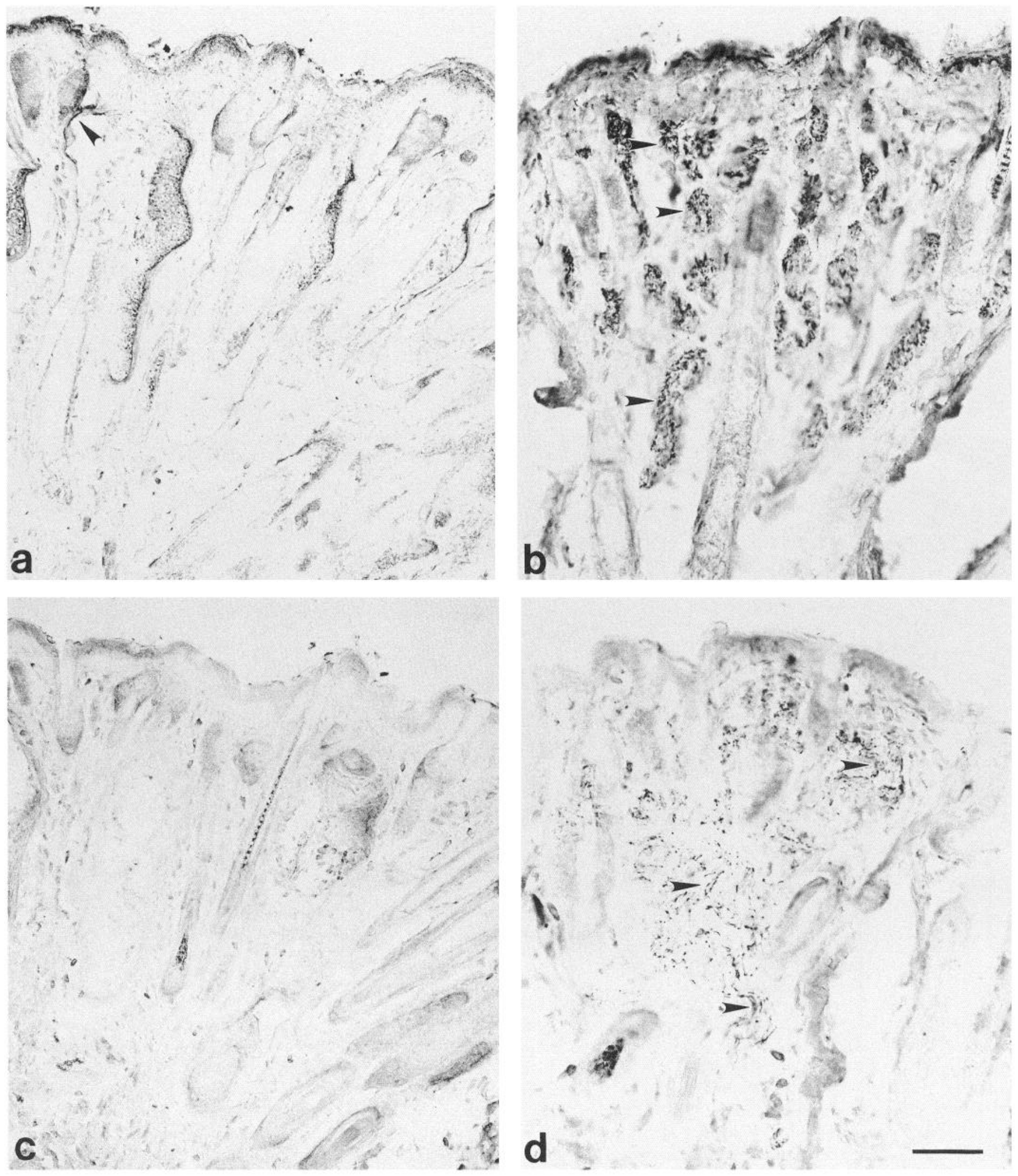

Figure 6. Immunolabeling of transgenic skin reveals a hyperinnervation of sensory and sympathetic neurons. To determine whether nerve processes in the A-56 skin contained sensory fibers, skin sections from the whisker pad region of control $(a)$ and an A-56 F1 transgenic $(b)$ were labeled using an anti-CGRP antibody followed by a biotinylated goat-anti rabbit secondary antibody and DAB processing. CGRP-positive fibers were scarce in control skin (a, arrowhead; note that edge labeling of vibrissal structures is artifactual), in contrast to transgenic skin (b), in which large numbers of positive fibers and nerve bundles were present. To examine peripheral sympathetic fibers, sections of control $(c)$ and transgenic $(d)$ skin were immunolabeled with an anti-TH antibody followed by a biotinylated goat-anti rabbit secondary antibody. TH-positive fibers, which were rare in control skin and seen primarily in the deep dermis encircling blood vessels (not visible), were markedly increased in the reticular layer of the dermis of transgenic skin (arrowheads). Scale bar, $50 \mu \mathrm{m}$. 


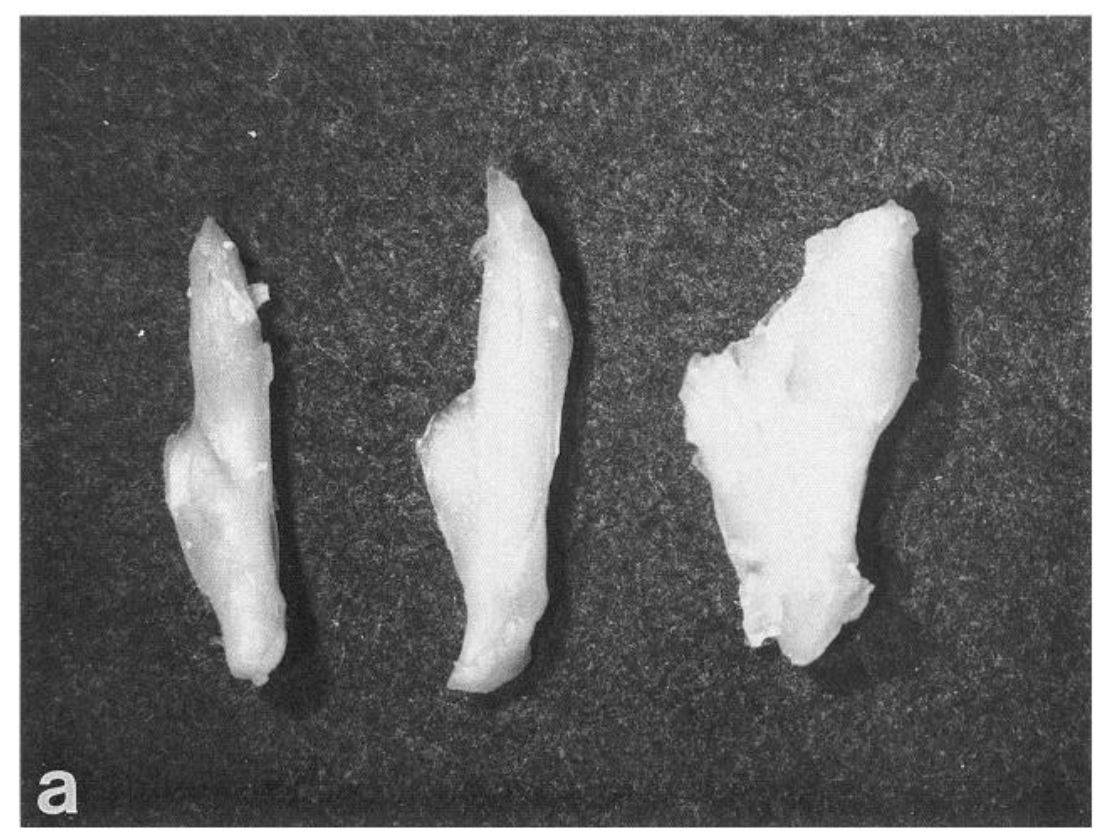

Figure 7. Expression of K14-NGF causes enlargement of the trigeminal and superior cervical ganglia. Trigeminal ganglia $(a)$ and superior cervical ganglia (b) were removed from control, A-47 F1, and A-56 F1 mice. For both the trigeminal and sympathetic superior cervical ganglia, controls (left) were smaller than either the A-47 (center) or A-56 ganglia (right). Scale bar, $1 \mathrm{~mm}$.

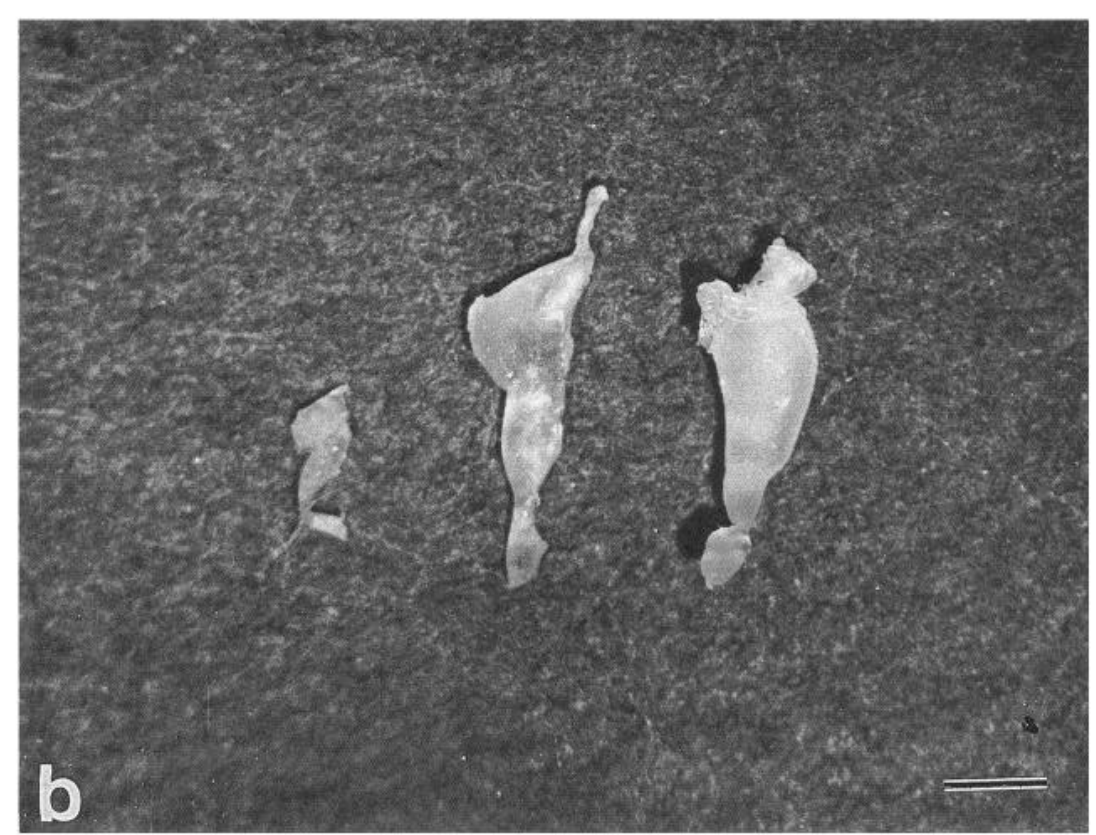

Whether all of the additional processes in the transgenic skin made functional synaptic contacts remains to be determined. However, for at least one type of sensory neuron, the highthreshold mechanoreceptor, recent evidence indicates an increase in functional terminals does occur. Measurements of mechanical sensitivity of the skin indicated a significant lowering of thresholds for both K14-NGF transgenic lines when compared to controls (Davis et al., 1993). These results support the presence of an increase in the number of functional sensory connections in the skin, though hypersensitivity may also have occurred due to peripheral or central (i.e., spinal) changes resulting from increased levels of NGF peptide (Lewin et al., 1993).

In the developing vertebrate nervous system the percentage of neurons that die is characteristic for each cell type. For sensory neurons of the vestibular and cochlear ganglia $25 \%$ of neurons die (Ard and Morest, 1984), whereas over $75 \%$ of neurons in the trigeminal mesencephalic nucleus die (Rogers and Cowan, 1974). During normal mouse development, the maximum number of cells in the trigeminal ganglia is found at E13 (Davies and Lumsden, 1984). These values are twice that measured at postnatal day 4 , indicating that up to $50 \%$ of neurons initially present underwent cell death. Mice expressing the K14-NGF transgene had, on average, approximately double the number of cells in their trigeminal ganglia when compared to controls. Since numerous studies have shown that the survival of NGFsensitive neurons is dependent on the local concentration of NGF, the most likely explanation for the increased cell number is that the supernormal levels of NGF generated by K14-NGF expression in the target prevented cell death. Similarly, prelim- 
inary studies of the superior cervical ganglion indicate that these NGF-sensitive neurons also had enhanced survival percentages (unpublished observations).

Another possibility for the increased cell survival in the trigeminal ganglia is that additional neurogenesis was induced by elevated NGF levels. NGF can act as a mitogen in primary chromaffin cell cultures (Lillian and Claude, 1985) and cells in the antcrior pituitary (Borrelli ct al., 1992), and as a mciotic growth factor during spermatogenesis (Parvinen et al., 1992). However, if NGF does exert a mitogenic effect on peripheral neurons it must occur prior to the first 4-6 weeks of postnatal development (the age at which animals were examined), since we observed no mitotic figures in the trigeminal ganglia despite examination of over 4000 cells/ganglia. In addition, the K14NGF transgene is active after the period of normal cell birth at a time when sensory neurons have completed their migration and extended processes into the periphery. Typically, sensory neurons that are this highly differentiated do not undergo neurogenesis (Pannese, 1974).

Though cell survival was higher in the transgenic ganglia, it is unclear whether all of the additional anti-NF 150-labeled fibers in the skin can be accounted for by increased survival. Another possibility is that axonal branching (sprouting) contributed to the increase in the peripheral nerve fibers. Injection of neonatal rodents with NGF peptide has been shown to induce extensive branching of sympathetic axons (Olson, 1967), as well as enhance dendritic arborizations of superior cervical ganglion neurons (Snider, 1988). Cutaneous sensory (Diamond et al., 1992) and sympathetic (Gloster and Diamond, 1992) fibers of adult rodents exposed to NGF also appear to undergo axonal spouting, as measured by the expansion of behaviorally responsive sensory fields. Whether production of NGF by the transgenic epidermis acted to promote sprouting in a similar fashion to injected NGF is unclear. Further study of sensory and sympathetic projections to the K14-NGF transgenic skin will be required to resolve this issue.

The effects we have observed on primary sensory afferents and sympathetic fiber innervation provide an interesting comparison to those reported by Edwards et al. (1989), which examined the effect of NGF on innervation of the pancreas. In this study the rat insulin promotor was utilized to overexpress an NGF cDNA in islet cells of the pancreas. Hyperinnervation of the islets was observed, though the source of innervating fibers appeared to be restricted to sympathetic postganglionic neurons. No apparent effect of increased NGF was observed on sensory fibers. From this finding it was proposed that the selective influence on sympathetic axons was due to an unidentified cofactor(s) that supported hyperinnervation of sympathetic but not sensory axons. This type of mechanism may be applicable to skin, but would require that the NGF responsive cofactor(s) be present for both systems since NGF overexpression caused both sympathetic and sensory hyperinnervation. Another possibility to explain the pattern of innervation in the NGF-expressing pancreas was that the overabundant sympathetic fibers outcompeted the sensory fibers for the available NGF. This mechanism would not he applicable to the K14-NGF transgenics since trigeminal cell counts indicate that the NGF-induced sensory survival was at or near maximal values.

Expression of K14-NGF mRNA was easily detectable in the transgenic epidermis by in situ hybridization and Northern analysis. Peptide concentration in transgenic skin and other tissues will also be important to evaluate in order to relate NGF con- centration to parameters such as cell survival and transmitter expression. Historically, NGF quantification in tissues is difficult because of low peptide levels and strong nonspecific binding of NGF to tissue components. To quantitate the amount of NGF peptide unequivocally, two-site immunoassays are required (Korsching and Thoenen, 1987). Preliminary measures of NGF in serum of A-56 transgenics using an in vitro bioassay have been made, however, to determine whether NGF levels were elevated. Results showed that in some but not all transgenic samples, NGF peptide could be detected. Transgenic values ranged between 5 and $30 \mathrm{ng} / \mathrm{ml}$, whereas in control sera NGF was never detected (P. Osborne and E. Johnson, personal communication). These results suggest that in some transgenics, sufficient amounts of NGF are being made to elevate serum NGF levels.

During development of the nervous system, the targets of neuronal innervation exert a major influence on cell survival by producing substances such as NGF and by providing sites of synaptic contact. By expressing NGF in the epidermis of transgenic mice we have created a model that allows examination of the effects of increased target-derived NGF on neuron survival. Our studies thus far have shown that the increased expression of NGF in the developing epidermis can inhibit, if not completely prevent, cell death. Moreover, the increase in the number of surviving neurons was independent of changes in the volume of the skin; that is, the target size remained the same. Thus, the amount of trophic factor production alone can regulate the number of surviving neurons. These results support the neurotrophic hypothesis and specifically demonstrate that the skin, by regulating the timing and amount of NGF expression independent of innervation, plays a central role in the development of the PNS.

\section{References}

Angeletti PU, Levi-Montalcini R, Caramia F (1971) Analysis of the effects of the antiserum to the nerve growth factor in adult mice. Brain Res 27:343-355.

Ard MD, Morest DK (1984) Cell death during development of the cochlear and vestibular ganglia of the chick. Int J Dev Neurosci 2:535547.

Barde Y-A, Edgar D, Thoenen H (1980) Sensory neurons in culture: changing requirements for survival factors during embryonic development. Proc Natl Acad Sci USA 77:1 199-1203.

Borrelli E, Sawchenko PE, Evans RM (1992) Pituitary hyperplasia induced by ectopic expression of nerve growth factor. Proc Natl Acad Sci USA 89:2764-2768.

Cheng J, Turksen K, Yu Q-C, Schreiber H, Teng M, Fuchs E (1992) Cachexia and graft-vs-host-disease-type skin changes in keratin promoter-driven TNF $\alpha$ transgenic mice. Genes Dev 6:1444-1456.

Chomczynski P, Sacchi N (1987) Single-step method of RNA isolation by acid guanidinium thiocyanate-phenol-chloroform extraction. Anal Biochem 162:156-159.

Coggeshall RE, Chung K, Greenwood D, Hulsebosch C (1984) An empirical method for converting nucleolar counts to neuronal numbers. J Neurosci Methods 12:125-132.

Coggeshall RE, La Forte R, Klein CM (1990) Calibration of methods for determining numbers of dorsal root ganglion cells. J Neurosci Methods 35:187-194.

Cowan WM, Fawcett JW, O'Leary DDM, Stanfield BB (1984) Regressive events in neurogenesis. Science 225:1258-1265.

Davies AM, Lumsden A (1984) Relation of target encounter and neuronal death to nerve growth factor responsiveness in the developing mouse trigeminal ganglion. J Comp Neurol 223:124-137.

Davies AM, Bandtlow C, Heumann R, Korsching S, Rohrer H, Thoenen $\mathrm{H}$ (1987) Timing and site of nerve growth factor synthesis in developing skin in relation to innervation and expression of the receptor. Nature 326:353-358.

Davies AM, Larmet Y, Wright E, Vogel KS (1991) Coordination of 
trophic interactions by separate developmental programs in sensory neurons and their target fields. J Cell Sci 15:111-116.

Davis BM, Lewin GR, Mendell LM, Jones ME, Albers KM (1993) Altered expression of nerve growth factor in the skin of transgenic mice leads to changes in response to mechanical stimuli. Neuroscience, in press.

Diamond J, Ilolmes M, Coughlin M (1992) Endogenous NGF and nerve impulses regulate the collateral sprouting of sensory axons in the skin of the adult rat. J Neurosci 12:1454-1466.

Donnerer J, Schuligoi R, Stein C (1992) Increased content and transport of substance $P$ and calcitonin gene-related peptide in sensory nerves innervating inflamed tissue: evidence for a regulatory function of nerve growth factor in vivo. Neuroscience 49:693-698.

Edwards RH, Rutter WJ, Hanahan D (1989) Directed expression of NGF to pancreatic $\beta$ cells in transgenic mice leads to selective hyperinnervation of the islets. Cell 58:161-170.

Gibbins IL, Wattchow D, Coventry B (1987) Immunohistochemically identified populations of calcitonin gene-related peptide-immunoreactive (CGRP-IR) axons in human skin. Brain Res 414:143-148.

Gloster A, Diamond J (1992) Sympathetic nerves in adult rats regencrate normally and restore pilomotor function during an anti-NGF treatment that prevents their collateral sprouting. J Comp Neurol 325:1-12.

Gorin PD, Johnson EM (1980) Effects of long term nerve growth factor deprivation on the nervous system of the adult rat: an experimental autoimmune approach. Brain Res 198:27-42.

Hamburger V, Yip HW (1984) Reduction of experimentally induced neuronal death in spinal ganglia of the chick embryo by nerve growth factor. J Neurosci 4:767-774.

Harper SJ, Davies AM (1990) NGF mRNA expression in developing cutaneous epithelium related to innervation density. Development $110 \cdot 515-519$

Hogan B, Costantini F, Lacy E (1986) Manipulating the mouse embryo: a laboratory manual. Cold Spring Harbor, NY: Cold Spring Harbor Laboratory.

Hsu SM, Raine L, Fanger H (1981) Use of avidin-biotin-peroxidase complex $(\mathrm{ABC})$ in immunoperoxidase techniques. A comparison between $\mathrm{ABC}$ and unlabeled antibody (PAP) procedures. J Histochem Cytochem 29:577-580.

Johnson E, Yip HK (1985) Central nervous system and peripheral nerve growth factor provide trophic support critical to mature sensory neuronal survival. Nature 314:751-752.

Johnson EM, Gorin PD, Brandeis LD, Pearson J (1980) Dorsal root ganglion neurons are destroyed by exposure in utero to maternal antibody to nerve growth factor. Science 210:916-918.

Kopan R, Fuchs E. (1989) A new look into an old problem: keratins as tools to investigate determination, morphogenesis, and differentiation in skin. Genes Dev 3:1-15.

Korsching S, Thoenen H (1983) Nerve growth factor in sympathetic ganglia and corresponding target organs of the rat: correlation with the density of sympathetic innervation. Proc Natl Acad Sci USA 80: 3513-3516.

Korsching S, Thoenen H (1987) Two-site enzyme immunoassay for nerve growth factor. Methods Enzymol 147:167-185.

Kruger L, Silverman JD, Mantyh PW, Sternini C, Brecha NC (1989) Peripheral patterns of calcitonin gene-related peptide general somatic sensory innervation: cutaneous and deep terminations. J Comp Neurol 280:291-302.

Levi-Montalcini R, Angeletti PU (1968) Nerve growth factor. Physiol Rev 48:534-569.

Levi-Montalcini R, Booker B (1960a) Excessive growth of the sympathetic ganglia evoked by a protein isolated from mouse salivary glands. Proc Natl Acad Sci USA 46:373-384.

Levi-Montalcini R, Booker B (1960b) Destruction of the sympathetic ganglia in mammals by an antiserum to a nerve-growth protein. Proc Natl Acad Sci USA 46:384-391.

Lewin GR, Ritter AM, Mendell LM (1993) Nerve growth factor- induced hyperalgesia in the neonatal and adult rat. $\mathrm{J}$ Neurosci 13 : $2136-2148$

Lillian LE, Claude P (1985) Nerve growth factor is a mitogen for cultured chromaffin cells. Nature 37:632-634.

Lindsay RM, Harmer AJ (1989) Nerve growth factor regulates expression of neuropeptide genes in adult sensory neurons. Nature 337 362-364.

Olson L (1967) Outgrowth of sympathetic adrenergic neurons in mice treated with a nerve-growth factor (NGF). Z Zellforsch Mikrosk Anat 81:155-173.

Oppenheim RW (1981) Neuronal death and some related phenomena during neurogenesis: a selective historical review and progress report. In: Studies in developmental biology (Cowan WM, ed), pp 74-133. New York: Oxford UP.

Oppenheim RW (1991) Cell death during development of the nervous system. Annu Rev Neurosci 14:453-501.

Pannese E (1974) The histogenesis of the spinal ganglia. Adv Anat Cell Biol 47:6-91

Parvinen M, Pelto-Huikko M, Soder O, Schultz R, Kaipia A, Mali P, Toppari J, Hakovirta H, Lonnerberg P, Ritzen EM, Ebendal T, Olson L, Hokfelt T, Persson H (1992) Expression of $\beta$-nerve growth factor in rat seminiferous epithelium: specific function at the onset of meiosis. J Cell Biol 117:629-642.

Rogers LA, Cowan WM (1974) The development of the mesencephalic nucleus of the trigeminal nerve in the chick. J Comp Neurol 147: 291-320.

Rohrer H, Heumann R, Thoenen H (1988) Synthesis of nerve growth factor (NGF) in developing skin is independent of innervation. Dev Biol 128:240-244.

Rothman TP, Specht LA, Gershon MD, Joh TH, Teitelman G, Pickel VM, Reis DJ (1980) Catecholamine biosynthetic enzymes are expressed in replicating cells of the peripheral but not the central nervous system. Proc Natl Acad Sci USA 77:6221-6225.

Ruit KG, Osborne PA, Schmidt RE, Johnson EM, Snider WM (1990) Nerve growth factor regulates sympathetic ganglion cell morphology and survival in the adult mouse. J Neurosci 10:2413-2419.

Sandgren EP, Luetteke NC, Palmiter RD, Brinster RL, Lee DC (1990) Overexpression of TGF alpha in transgenic mice: induction of epithelial hyperplasia, pancreatic metaplasia, and carcinoma of the breast Cell 61:1121-1135.

Schecterson LC, Bothwell M (1992) Novel roles for neurotrophins are suggested by BDNF and NT-3 mRNA expression in developing neurons. Neuron 9:449-463.

Schweizer J, Winter H (1982) Keratin polypeptide analysis in fetal and in terminally differentiating newborn mouse epidermis. Differentiation 22:19-24

Shelton DL, Reichardt LF (1984) Expression of the beta-nerve growth factor gene correlates with the density of sympathetic innervation in effector organs. Proc Natl Acad Sci USA 81:7951-7955.

Shotzinger RJ, Landis SC (1990) Postnatal development of autonomic and sensory innervation of thoracic hairy skin in the rat. Cell Tissue Res 260:575-587.

Snider WD (1988) Nerve growth factor enhances dendritic arborization of sympathetic ganglion cells in developing mammals. J Neurosci 8:2628-2634.

Thoenen H, Barde Y-A (1980) Physiology of nerve growth factor. Physiol Rev 60:1284-1334.

Ullich A, Gray A, Berman C, Dull TJ (1983) Human $\beta$-nerve growth factor gene sequence highly homologous to that of mouse. Nature 303:821-825.

Vassar R, Rosenberg M, Ross S, Tyner A, Fuchs E (1989) Tissuespecific and differentiation-specific expression of a human K14 keratin gene in transgenic mice. Proc Natl Acad Sci 86:1563-1567.

Vassar R, Coulombe PA, Degenstein L, Albers K, Fuchs E (1991) Mutant keratin expression in transgenic mice causes marked abnormalities resembling a human genetic skin disease. Cell 64:365-380. 